\title{
MOLECULAR EVALUATION OF -75G/A AND +83C/T APOLIPOPROTEIN A-1 GENE POLYMORPHISMS IN NON ALCOHOLIC FATTY LIVER DISEASE
}

\author{
Mohamed Y. Nasr ${ }^{1}$, Risk El-Baz ${ }^{2}$, Hesham S. Abd-Elsabour ${ }^{3}$, Amal A. Abd-Elaziz ${ }^{1}$ \\ ${ }^{1}$ Molecular Biology Department, Genetic Engineering and Biotechnology Research Institute (GEBRI), \\ University of Sadat City, Egypt. \\ ${ }^{2}$ Department of Biochemistry, Faculty of Medicine, Mansoura University, Mansoura, Egypt. \\ ${ }^{3}$ B.Sc., Laboratory Technology, MUST, Egypt.
}

\begin{abstract}
Apolipoprotein A-1 (APOA1) is the major protein component of High Density Lipoprotein in plasma, promotes cholesterol efflux from tissues to the liver for excretion, it is a cofactor for Lecithin Cholesterolacyl Transferase (LCAT) which is responsible for the formation of most plasma cholesteryl esters. Therefore, the main objective of the present study was carried out to investigate the association of APOA1 gene polymorphisms among patients with Non Alcoholic Fatty Liver Disease (NAFLD) by using PCRRFLP analysis. Samples were collected from 100 cases affected with NAFLD as well as 100 healthy samples as a negative control. APOA1 $+83 \mathrm{C} / \mathrm{T}$ gene polymorphism was showed that CC genotype was significantly higher frequency $(p=0.0001)$ in healthy control than cases $(70 \%$ vs. $10 \%)$, CT genotype was significantly higher frequency $(p=0.001)$ in cases than healthy control $(65 \%$ vs. $25 \%)$ and TT genotype was significantly higher frequency $(p=0.001)$ in cases than healthy control ( $25 \%$ vs. $5 \%)$. Regarding all types of APOA1 75G/A gene polymorphism, they were showed that all cases were non-significantly $(p>0.05)$ when compared to healthy control. So, NAFLD among Egyptian was strongly associated with mutations related to APOA1 gene polymorphism especially APOA1 +83C/T gene polymorphism.
\end{abstract}

Key words: Polymorphisms; Nonalcoholic fatty liver disease; APOA1 gene.

\section{INTRODUCTION}

Nonalcoholic fatty liver disease (NAFLD) is common and may Progress to cirrhosis and its complications. The pathogene of steatosis and cellular injury is thought to be related mostly to insulin resistance and oxidative stress. Therefore, management entails identification and treatment of metabolic risk factor, improving insulin sensetivity, and increasing antioxidant defences in the liver. Weight loss and exercise improve insulin sensitivity. Bariatric surgery may improve liver histology in patients with morbid obesity. Insulin sensitising drugs showed promise in pilot trials as have a number of hepatoprotective agents. Further randomised, well controlled trials are required to determine the efficacy of these drugs (1).
The optimal diet to treat NAFLD is not known. Patients with NAFLD seem more likely to have a diet high in saturated fats and cholesterol and low in fibre and antioxidants (2) Mono and poly unsaturated fats may potentially improve insulin resistance and may be beneficial in improving hepatic steatosis. . Most trials have used a diet similar to that recommended by the American Heart Association with energy restriction and energy intake composed of $40 \%-50 \%$ carbohydrates, $15 \%-20 \%$ protein, and $25 \%-40 \%$ predominately unsaturated fats (3).

Several studies have examined weight loss in obese children with NAFLD. Diet and exercise leading to roughly $500 \mathrm{~g} /$ week weight loss in nine children, led to improvement in aminotransaminases and hepatic steatosis as determined by ultrasound. Similarly, weight loss 
from diet (1200-1400 calories/day) and exercise (at least six hours/week) was evaluated in 33 obese children aged between 4 and 16 years.Weight loss was associated with normalisation of liver tests and improvement or normalisation of hepatic steatosis on ultrasound. Improvement in aminotransaminases has also been reported in a series of six children with NAFLD, with fluctuating liver enzymes reported in those unable to lose weight (4).

Apolipoproteins

are proteins that bind lipids (oil-soluble substances such as fat and cholesterol) to form lipoproteins. They transport the lipids through the lymphatic and circulatory systems Apolipoprotein A1 is a major protein that is a component of high-density liporprotein, or HDL cholesterol. Also known as Apo A1, it helps clear cholesterol from the blood by removing cholesterol from organs and tissues to be destroyed by the liver, human apoA-1circulates in plasma primarily as a component of HDL. It is also present on chylomicrons but is rarely found in significant amounts on VLDL or LDL. Apolipoprotein A-1 has two major sites of synthesis: the intestine and the liver (6).

Restriction site polymorphisms have been identified at $-75 \mathrm{bp}$ in the promoter region and $+83 \mathrm{bp}$ in intron 1 of the apo A1 gene Association of the +83 bp polymorphism with elevated levels of HDL cholesterol has been stronger than that with the -75 bp polymorphism (7). The genotype effect on circulating apo A1 and HDL cholesterol levels is modulated by sex and environmental factors such as smoking (8)\&(9). The differences in HDL cholesterol and apo A1 levels among various genotypes of the apo A1 gene are not modified by different diets, suggesting that the possible benefit is independent of fat and cholesterol intake (10).

\section{SUBJECTS AND METHODS}

\section{Subjects}

In the present study, Samples were collected from 100 cases affected with NAFLD, as well as, 100 healthy samples as a negative control, using PCR-RFLP analysis. NAFLD patients group had 21 males and 79 females. NAFLD patients age was ranged from 18 to 72 years with mean age = $(44.94 \pm 15.01)$ years. All cases were recruited from outpatient clinic, department of obesity and diabetes in Internal Medicine Specialized Hospital (IMSH), Mansoura University, Egypt. These cases were compared to other Negative control was selected including 100 healthy unrelated subjects randomly taken from blood donors, The healthy control group had 26 males and 74 females, their age was ranged from 19 to 65 years with mean age $=45.43 \pm 15.54$ years.

\section{Blood samples}

Peripheral blood was collected from the subjects in 2-ml EDTA tubes, and genomic DNA was isolated using a puregene DNA isolation kit.

\section{Sequence Specific Primers (SSP-PCR)}

In the present study the Sequence Specific Primers (SSP-PCR) method was used to detect and determine the polymorphisms -75G/A, and $+83 \mathrm{C} / \mathrm{T}$ genomic DNA was amplified. PCR amplification was performed in single SSP-PCR reaction employing a forward and a reverse primer for polymorphisms of (APOA1) gene. The regions containing RFLPs within the APOA1 gene were amplified with Taq DNA polymerase with gene specific primers

(Forward $5^{\prime}-$ AGgGACAGAGCTGATCCTTGAACTCTTAAG-3') and

(Reverse $5^{\prime}-$ TTAGGGGACACCTACCCGTCAGGAAGAGCA-3').

Briefly, The $29 \mu \mathrm{l}$ reaction volume contained 10 $\mu l$ of $2 X$ PCR Master Mix, $2 \mu$ of Forward primers, $2 \mu$ l of Reverse primers, $3 \mu$ l of DNA Sample and $12 \mu \mathrm{l}$ of distilled water. The amplification was carried out with the following cycling parameters: 240 seconds heat start at 
$94^{\circ} \mathrm{C}$, followed by 35 cycles of denaturation at $94^{\circ} \mathrm{C}$ for 30 seconds, annealing at $55{ }^{\circ} \mathrm{C}$ for 30 seconds, extension at $72{ }^{\circ} \mathrm{C}$ for 30 seconds for cycles and a final extension at $72^{\circ} \mathrm{C}$ for 7 mint. PCR products were visualized on $2 \%$ agarose gel. Afterwards, Eight microliters of PCR product was digested with $2.5 \mathrm{U}$ of the restriction enzyme Msp1 at $37^{\circ} \mathrm{C}$ for 4 hour, and the digested products were visualized on a $3 \%$ Ethidium bromide agarose gel, gel appeared the 433-bp amplicon into 254, 209, 179, and 113.

\section{Statistical analysis of the data}

The collected data in the present work were organized and statistically analyzed using SPSS statistical computer package software (version17) and post comparison was carried out with Fisher exact test corrected chi-square test, Odds ratio (OR)\& 95\% confidence interval $(95 \% \mathrm{Cl})$ and Independent Sample $\mathrm{T}$ test. The result were expresed as means \pm standard deviation (SD) for variables of age (years) of cases. The values of $P<0,05$ were considered statistically significant.

\section{RESULTS AND DISCUSSION}

\section{$+83 \mathrm{C} / \mathrm{T}$ genotype values}

Data represented in Table (1) shows comparisons among genotypes values between healthy controls and cases regarding APOA1 $+83 \mathrm{C} / \mathrm{T}$ gene polymorphism it was showed that $\mathrm{CC}$ genotype was significantly higher frequency in healthy control than cases $(70 \%$ vs. $10 \%$, OR $=0.0595 \% \mathrm{Cl}=(0.02-0.10))(\mathrm{p}=0.0001$, for each ). While $\mathrm{CT}$ genotype was significantly higher frequency in cases than healthy control $(65 \%$ vs. $25 \%, O R=5.5795 \% C l=(3.02-10.27) \quad(p=0.001$, for each). Also TT genotype was significantly higher frequency in cases than healthy control $(25 \%$ vs. $5 \%$ OR $=6.3395 \% \mathrm{Cl}=(2.31-17.33)$ $(p=0.001$, for each).

\section{-75G/A genotype values}

Data represented in Table (2) shows comparisons among polymorphic variants of Apo A1 -75 G/A gene polymorphism among all cases and controls. From this table, cases did not differ significantly from controls $(p>0.05)$ regarding all type of apo A1 -75 G/A polymorphism, although the frequency of GG genotype was higher among cases than healthy control $(92 \%$ vs. $86 \%$ OR $=1.87,95 \% \mathrm{Cl}=(0.75-$ 4.68). Also the frequency of AA genotype was higher among cases than healthy control (4\% vs. $0.0 \% \mathrm{OR}=0.49,95 \% \mathrm{Cl}=(0.42-0.56))$. While the frequency of the GA genotype was higher among healthy control than cases, ( $14 \%$ vs. $4 \%$, $\mathrm{OR}=3.83,95 \% \mathrm{Cl}=(1.21-12.07))$. Also $\mathrm{A}$ and $\mathrm{G}$ alleles showed no significant among all cases ( $p>0.05)$.

\section{Comparisons among+83 $\mathrm{C} / \mathrm{T}$ and $-75 \mathrm{G} / \mathrm{A}$ genotype of APOA1 gene}

Data represented in Table (3) shows comparisons among cases to controls as regard $+83 \mathrm{C} / \mathrm{T} \&-75 \mathrm{G} / \mathrm{A}$ polymorphisms it was noted that $\mathrm{GA} / \mathrm{CT}$ genotype of healthy control showed significantly higher frequency than cases $(14 \%$ vs. $4 \%, \mathrm{OR}=0.256,95 \% \mathrm{Cl}=(0.081-0.807)$ $(p=0.013)$. Also $G G / C C$ genotype of healthy control showed significantly higher frequency than cases $(70 \%$ vs. $10 \%, \mathrm{OR}=0.048,95 \% \mathrm{Cl}=$ $(0.22-0.104)(p=0.001)$, While GG/CT genotype of cases showed significantly higher frequency than control $(57 \%$ vs. $11 \%, \quad O R=10.725$, $95 \% \mathrm{Cl}=5.112-22.502)$ ( $p=0.001$ for each). Also GG/TT genotype of cases showed significantly higher frequency than control $(25 \%$ vs. $5 \%$ $O R=6.33,95 \% \mathrm{Cl}=(0.231-17.33) \quad(p=0.001$ for each). Also $A A / C T$ genotype of cases showed significantly higher frequency than control $(4 \%$ vs. $0 \%, O R=2.042,95 \% \mathrm{Cl}=(1.77-2.355)(p=$ 0.043). 
Table (1): Comparison of $+83 \mathrm{C} / \mathrm{T}$ genotype values among control and cases regarding APOA1 gene polymorphism

\begin{tabular}{|c|c|c|c|c|c|}
\hline \multirow[t]{2}{*}{ APOA1 +83 } & \multirow[t]{2}{*}{$N$} & $\begin{array}{l}\text { Cases } \\
(n=100)\end{array}$ & $\begin{array}{l}\text { Control } \\
(\mathrm{n}=100)\end{array}$ & \multirow[t]{2}{*}{$\mathbf{P}$} & \multirow[t]{2}{*}{ OR $(95 \% \mathrm{Cl})$} \\
\hline & & $\mathrm{N}(\%)$ & $\mathrm{N}(\%)$ & & \\
\hline \multirow{3}{*}{ Genotypes } & (CC) & $10(10 \%)$ & 70 (70\%) & $<0.001^{*}$ & $0.05(0.02-0.10)$ \\
\hline & (CT) & 65 (65\%) & $25(25 \%)$ & $<0.001 *$ & $5.57(3.02-10.27)$ \\
\hline & (TT) & $25(25 \%)$ & $5(5 \%)$ & $<0.001 *$ & $6.33(2.31-17.33)$ \\
\hline \multirow{2}{*}{ Alleles } & (C) & 85 (42.5\%) & 165 (82.5\%) & $<0.001 *$ & $0.16(0.10-0.25)$ \\
\hline & $(\mathrm{T})$ & 115 (57.5\%) & 35 (17.5\%) & $<0.001 *$ & $2.83(2.09-3.83)$ \\
\hline
\end{tabular}

$\mathrm{N}=$ number of subjects, significance using t-test or Chi-square test:

* Significant $\mathrm{P}<0.05$

$\mathrm{P}=$ cases vs. Controls

Table (2): Comparison of -75G/A genotype values among healthy control and cases regarding APOA1 gene polymorphism

\begin{tabular}{|c|c|c|c|c|c|}
\hline \multirow[t]{2}{*}{$-75 G / A$} & APOA1 & $\begin{array}{l}\text { Cases } \\
(\mathrm{n}=100)\end{array}$ & $\begin{array}{l}\text { Control } \\
(n=100)\end{array}$ & \multirow[t]{2}{*}{$\mathbf{P}$} & \multirow[t]{2}{*}{ OR $(95 \% \mathrm{Cl})$} \\
\hline & & $\mathrm{N}(\%)$ & $N(\%)$ & & \\
\hline \multirow{3}{*}{ Genotypes } & (GG) & 92 (92\%) & 86 (86\%) & 0.175 & $1.87(0.75-4.68)$ \\
\hline & (GA) & $4(4 \%)$ & 14 (14\%) & $0.015^{*}$ & $3.83(1.21-12.07)$ \\
\hline & (AA) & $4(4 \%)$ & $0(0 \%)$ & $0.041^{*}$ & $0.49(0.42-0.56)$ \\
\hline \multirow{2}{*}{ Alleles } & (G) & 188 & 186 & $>0.05$ & $1.18(0.53-2.62)$ \\
\hline & (A) & 12 & 14 & $>0.05$ & $0.92(0.64-1.34)$ \\
\hline
\end{tabular}

$\mathrm{N}=$ number of subjects, significance using $\mathrm{t}$-test or Chi-square test:

* Significant $\mathrm{P}<0.05$

$\mathrm{P}=$ cases vs. Controls 
Table (3): Comparison of the combined genotype frequency among healthy control and cases regarding $+83 \mathrm{C} / \mathrm{T}$ and $-75 \mathrm{G} / \mathrm{A}$ genotype of APOA1 gene

\begin{tabular}{|c|c|c|c|c|}
\hline & Cases & Control & P value & OR (95\% Cl) \\
\hline GG/CC & $10(10 \%)$ & $70(70 \%)$ & $<0.001^{*}$ & $0.048(0.22-0.104)$ \\
\hline GG/TT & $25(25 \%)$ & $5(5 \%)$ & $<0.001^{*}$ & $6.33(2.31-17.33)$ \\
\hline GG/CT & $57(57 \%)$ & $11(11 \%)$ & $<0.001^{*}$ & $10.725(5.112-22.502)$ \\
\hline AA/CT & $4(4 \%)$ & $0(0 \%)$ & $0.043^{*}$ & $2.042(1.77-2.355)$ \\
\hline GA/CT & $4(4 \%)$ & $14(14 \%)$ & $0.013^{*}$ & $0.256(0.081-0.807)$ \\
\hline
\end{tabular}

$\mathrm{N}=$ number of subjects, significance using t-test or Chi-square test:

* Significant $P<0.05$

$\mathrm{P}=$ cases vs. Controls

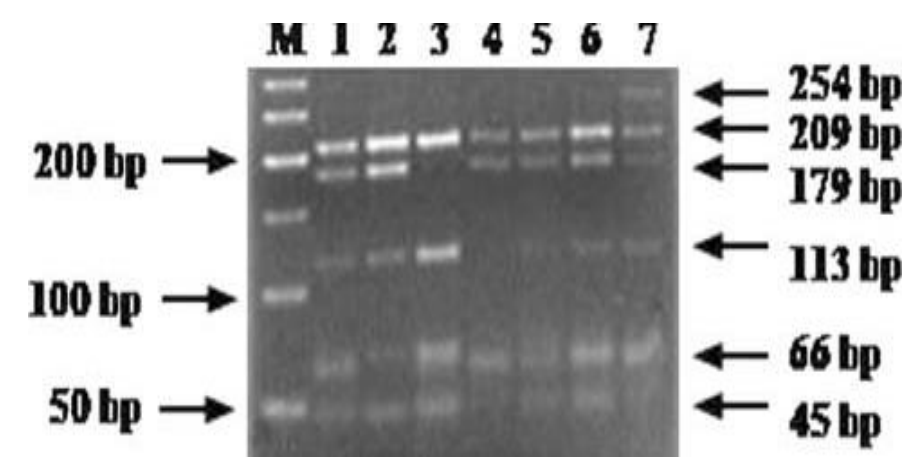

Fig (1): showed cases of $-75 \mathrm{G} / \mathrm{A}$ and $+83 \mathrm{C} / \mathrm{T}$ polymorphisms of APOA1 gene

Restriction fragment length polymorphism (RFLP) on 3\% agarose gel. At lane 1, 2, 5 and 6 there were triple bands 209,179,113bp which refer to GG/CT genotype. At lane 3 there is double bands 209, $113 \mathrm{bp}$ which refer to GG/CC genotype, At lane 4 there is double bands 209 \&179 bp which refer to GG/TT genotype, At lane 7 there is 4 bands 254, 209, 179, 113 bp which refer to GA/CT genotype. M DNA marker $50 \mathrm{bp}$.

Nonalcoholic fatty liver Diseases (NAFLD) has beccome recognized as one of the most common abnormalities observed in obese individuals (11). It refered to a wide spectrum of liver damage, ranging from simple steatosis to steatohepatitis, advanced fibrosis, and cirrhosis. Overall, NAFLD has been reported to affect $10 \%$ to $24 \%$ of populations of various countries and up to $74 \%$ of obese individuals (12). NAFLD is associated with alteration in lipoprotein metabolism resulting in an atherogenic lipid profile with increase in total cholesterol (TC), triglycerides (TG), low density lipoprotein cholesterol (LDL-C), very low density lipoprotein cholesterol (VLDL) and reduced level of high density cholesterol (HDL-C) (13) (14). NAFLD might be complicated by disorders like diabetes mellitus,Diabetes mellitus associated with 
NAFLD is a complex metabolic disorder characterized by persistent hyperglycemia resulting from defects in insulin secretion, insulin action or both (15). There are also changes to apolipoprotein composition in diabetic patients with increased susceptibility of apolipoproteins $A 1$ and $B$ to glycation which results in decreased affinity for HDL receptors and increased susceptibility to oxidative modification

(16).

In the present, study from the cumulative data concluded that there was no relationship between -75(G/A) polymorphism and serum lipid HDL-cholesterol levels when patient values were compared to those of the controls $(p<0.05)$ (17). Also another study suggested that Non difference in apoA1G-75A genotype or allele frequency distributions between the controls and patients were identified. Howerver, there was a significantly lower frequency of the CT genotype $(p=0.012)$ and T allele $(p=0.011)$ in the affected subjects with hypercholesterolaemia or hypertension. Triglyceride levels were significantly lower in the subjects with the CT genotype compared to those with the CC genotype $(p<0.05)$. The $G-75 A$ genotypes did not appear to influence the lipid or blood pressure levels. The +83 T allele may be associated with a better lipid profile and blood pressure levels in this group of Chinese subjects (18).

The result of the current work demonstrated that the levels of serum TC, TG, HDL-C and LDL-C were significantly higher than those in healthy control individuals. In addition, the study has compared the liver function tests, $\mathrm{CBC}$, ctreat, HBA1C and lipid levels of $-75 G / A \&+83 C / T$ combind genotype of apoA1 gene and noted that all values levels between all combined genotype groups showed no significant, while serum TG level was significantly higher in GG/TT genotype than GG/CC genotype. Also, this study observed that all values levels of $+83 C / T$ genotype of apo $\mathrm{A} 1$ gene showed no significant difference among the three groups (CC/CT/TT).
While the serum TG level in CC genotype was significantly lower than those in TT genotype. Also the study compared the liver function tests,CBC, HBA1c,ctreat and lipid levels of-75G/A genotype of apoA1 gene and showed no significant, Also the frequency of $A A$ genotype was higher than GG genotype in TG,TC, LDL-C and HDL-C serum levels. While GG genotype was higher than frequency $A A$ genotype in ALB and HBA1c serum levels, Also, this study observed that the mutated homozygous TT \& heterozygous CT genotype \& mutant $\mathrm{T}$ allele of $+83 \mathrm{C} / \mathrm{T}$ polymorphism had a significantly higher frequency among NAFLD cases compared to healthy control. So CT, TT genotype \& $\mathrm{T}$ allele may be considered as genetic risk factors for NAFLD cases. Also the result found that wild $\mathrm{CC}$ genotype and $\mathrm{C}$ alleles of $+83 \mathrm{C} / \mathrm{T}$ polymorphism had significantly higher frequency among healthy controls compared to NAFLD cases. So, CC genotype and $\mathrm{C}$ allele may be considered as protective factors against the development of NAFLD.

Comparisons among the results of the current work with populations obesity, the -75G/A polymorphism, A allele frequency was (6.5\%) in the the present study. The frequency was close to Brazilian (10.2\%) (19), Nigerians (10.1\%) (21), other European populations (11.2-15.5\%) (20), (22), (23), on other hand A allele was lower than Taiwanese (32\%) (24), Spanish (20.3-24\%) (25), and omani (22\%) (26), Also, The frequency of T allele was $(57.5 \%)$ in the present study, the results of the current work was higher than the frequency of Brazilian (21\%) (35), Nigerian (40.2\%) (21), Chinese (4\%), Malays (3\%) and Indians (2\%) from Singapore (27), Omani (6.7\%) (26) and Australian (4.1\%) (28).

In conclusion, the data of the present study concluded that $+83 \mathrm{C} / \mathrm{T}$ and $-75 \mathrm{G} / \mathrm{A}$ polymorphisms of apo $\mathrm{A} 1$ gene were found to be associated with development of NAFLD Egyptian patients. Mutant T allele, CT and TT genotypes of $+83 \mathrm{C} / \mathrm{T}$ polymorphism may be 
considered genetic risk factors for development of NAFLD, there was no relationship between mutant $A$ allele of $-75 \mathrm{G} / \mathrm{A}$ polymorphism and NAFLD. Maximum risk combined genotypes included ( $G G$ and $C C$ ), (GG and TT) and ( $G G$ and $\mathrm{CT}$ ) may be consider genetic risk factor. So, This study recommend that studying $+83 \mathrm{C} / \mathrm{T}$ and $-75 \%$ G/A polymorphisms of APOA1 gene using simple technique as SSP-PCR can be used as a marker for NAFLD and analysis of these polymorphisms among familial cases.

\section{REFERENCES}

(1). Adoms LA., and Angulo P. (2006). Treatment of non alcoholic fatty liver disease. Post gradmend J., 82 (967): 315-322.

(2). Mottin C C., Moretto M., and Padoin A V. (2004). The role of ultrasound in the diagnosis of hepatic steatosis in morbidly obese patients. Obes Surg., 14635-637.

(3). Musso G., Gambino R. De., and Michieli F. (2003). Dietary habits and their relations to insulin resistance and postprandial lipemia in nonalcoholic steatohepatitis. Hepatology, 37909-916.

(4). Huang M. A., Greenson J. K., and Chao C. (2005). One year intense nutritional counseling results in histological improvement in patients with nonalcoholic steatohepatitis: a pilot study. Am J Gastroenterol., 1001072-1081.

(5). Rashid M., and Roberts E. A. (2000). Nonalcoholic steatohepatitis in children. J Pediatr Gastroenterol Nutr., 3048-53.

(6). Fidge N. H., Nestel P. J., Ishikawa T., Reardon M., and Billington T. (2000). Turnover of apoproteins $A-I$ and $A-I I$ of high density lipoprotein and the relationship to other lipoproteins in normal and hyperlipidemic individuals. Metabolism. 29: 643-653.

(7). Wang XL., Liu SX., McCredie RM., and Wilcken DE. (2002). Polymorphism at the 5 end of the apolipoprotein A1 gene and severity of coronary artery disease. J Clin Invest., 98: 372-7.

(8). Sigurdsson G. Jr., Gudnason V., Sigurdsson G., and Humphries SE. (2000). Interaction between a polymorphism of the apo A1 promoter region and smoking determines plasma levels of $\mathrm{HDL}$ and apo A1. Arterioscler Thromb., 12: 1017-1022.

(9). Talmud P.J., Ye S., and Humphries SE. (2000). Polymorphism in the promoter region of the apolipoprotein $\mathrm{A} 1$ gene associated with differences in apolipoprotein A1 levels: the European Atherosclerosclerosis Research Study. Genet Epidemiol, 11 (3): 265-80.

(10). Meng QH., Pajukanta P., Valsta L., Aro A., Pietinen P., and Tikkanen MJ. (2003). Influence of apolipoprotein A1 promoter polymorphism on lipid levels and responses to dietary change in Finnish adults. J Intern Med., 241: 373-378.

(11). Saadeh S. (2007). Nonalcoholic fatty liver disease and obesity. Nutr clin pract., 22 (1): 1-10.

(12). Angulo P. (2002). Treatment of nonalcoholic fatty liver disease. Ann Hepatol., 1 (1): 12-9.

(13). Hubert HB., Feinleib M., McNamara PM., and Castelli WP. (1993). Obesity as an independent risk factor for cardiovascular disease: a 26-year follow-up of participants in the Framingham Heart Study. Circulation., 67 (5): 968-77. 
(14). Grundy SM., and Barnett JP. (2000). Metabolic and health complications of obesity. Dis Mon., 36 (12): 641-731.

(15). Rother KI. (2007). Diabetes treatment-bridging the divide.N Engl J med., 356 (15): 1499-501.

(16). Hedrick CC., Thorpe SR., Fu MX., Harper CM., Yoo J, Kim SM, Wong H., and Peters AL. (2000). Glycation impairs high-density lipoprotein function. Diabetologia., 43 (3): 312-20.

(17). Toptas B., Gormus U., Ergen A., Gurkan H., Kelesoglu F., Darendeliler F., Bas F., Dalan AB., Izbirak G., and Isbir T. (2011). Comparison of lipid profiles with APOA1 Mspl polymorphism in obese children with hyperlipidemia. In Vivo., 25 (3): 425-30.

(18). Chen ES., Mazzotti DR., Furuya TK., Cendoroglo MS., Ramos LR., Araujo LQ., Burbano RR., and Arruda De., Smith M. (2009). Apolipoprotein A1 gene polymorphisms as risk factors for hypertension and obesity. Clin Exp Med., 9 (4): 319-25.

(19). Ma YQ., Thomas GN., and Tomlinson B. (2005). Association of two apolipoprotein A1 gene Mspl polymorphisms with lipid and blood pressure levels. Int J Cardiol., 102 (2): 309-14.

(20). Talmud PJ., Ye S., and Humphries SE. (1994). Polymorphism in the promoter region of the apolipoprotein $\mathrm{A} 1$ gene associated with differences in apolipoprotein A1 levels : the European Atherosclerosclerosis Research Study. Genet Epidemiol., 11 (3): 265-80.
(21). Kamboh MI., Aston CE., Nestlerode CM., McAllister AE., and Hammman RF. (1999). Haplotype analysis of two APOA1/Mspl polymorphisms in relation to plasma levels of apo A1 and HDL-cholesterol. Atherosclerosis.,127 (2): 255-62.

(22). Jeenah M., Kessling A., Miller N., and Humphries SE. (1997). G to A substitution in the promoter region of the apolipoprotein $\mathrm{A} 1$ gene is associated with elevated serum apolipoprotein A1 and high density lipoprotein cholesterol concentrations. Mol Biol Med., 7: 233-41.

(23).Minnich A., DeLangavant G., Lavigne J., Roederer G., Lussier-Cacan S., and Davignon J. (1995). G/A substitution at position -75 of the apolipoprotein A1 gene promoter. Evidence against a direct effect on HDL cholesterol levels.Arterioscler Thromb Vasc Biol., 15: 1740-1745.

(24). Wu AL., and Windmueller HG. (2000). Relative contribution by liver and intestine to individual plasma apolipoproteins in the rat. J Biol Chem., 254 (15): 7316-22.

(25). Morcillo S., Cardona F., Rojo-Martinez G., Esteva I., Ruiz-de-Adana MS., Tinahones F., Gomez-Zumaquero JM., and Soriguer F. (2005). Association between Mspl polymorphism of the APO A1 gene and type 2 diabetes mellitus. Diabet Med., 22: 782-788.

(26). Al-Yahyaee SA., Al-Kindi MN., and Al-Bahrani Al. (2004). Apolipoprotein A1 gene polymorphisms at the $-75 \mathrm{bp}$ and $+83 / 84$ bp polymorphic sites in healthy Omanis compared with world populations. Hum Bio., 76: 307-312. 
(27). Heng CK., Low PS., and Saha N. (2001). Variations in the promoter region of the apolipoprotein A1 gene influence plasma lipoprotein A levels in Asian Indian neonates from Singapore. Pediatr Res., 49: 514-518.

(28). Wang XL., Badenhop R., Humphrey KE., and Wilcken DE. (1996). New Mspl polymorphism at $+83 \mathrm{bp}$ of the human apolipoprotein A1 gene: association with increased circulating high density lipoprotein cholesterol levels. Genet Epidemiol., 13: 1-10. 